\title{
Grid-tie three-phase inverter with active power injection and reactive power compensation
}

\author{
Leonardo P. Sampaio ${ }^{\text {a, }}{ }^{*}$, Moacyr A.G. de Brito ${ }^{b}$, Guilherme de A. e Melo ${ }^{c}$, \\ Carlos A. Canesin ${ }^{\mathrm{C}}$ \\ a Federal Technological University of Paraná, UTFPR, Av. Alberto Carazzai 1640, Cornélio Procópio, PR, Brazil \\ b Federal Technological University of Paraná, UTFPR, Via Rosalina Maria dos Santos 1233, Campo Mourão, PR, Brazil \\ c São Paulo State University, UNESP, Av. Prof. José Carlos Rossi 1370, Ilha Solteira, SP, Brazil
}

\section{A R T I C L E I N F O}

\section{Article history:}

Received 14 February 2014

Received in revised form

16 May 2015

Accepted 11 July 2015

Available online 25 July 2015

\section{Keywords:}

Distributed generation

Power flow control

Microgrid

Linear matrix inequalities

Feedback linearization

Robust control

\begin{abstract}
A B S T R A C T
This paper proposes a methodology for the active and reactive power flow control, applied to a grid-tie three-phase power inverter, considering local and/or regionalized power flow control necessity in the forthcoming distributed generation scenario. The controllers are designed by means of robust pole placement technique, which is determined using the Linear Matrix Inequalities with D-stability criteria. The linearized models used in the control design are obtained by means of feedback linearization, aiming to reduce system nonlinearities, improve the controller's performance and mitigate potential disturbances. Through multi-loop control, the power loop uses active and reactive power transfer adapted expressions to obtain the magnitude of the voltage and power transfer angle to control the power flow between the distributed generation and the utility grid. The methodology main idea is to obtain the best controllers with the lowest gains as possible placing the poles in the left-half s-plane region, resulting in fast responses with reduced oscillations. In order to demonstrate the feasibility of the proposal a $3 \mathrm{kVA}$ three-phase prototype was implemented and a comparison with conventional controller is performed to demonstrate the proposed methodology performance. In addition, anti-islanding detection and protection against over/under voltage and frequency deviations are demonstrated through experimental results.
\end{abstract}

() 2015 Elsevier Ltd. All rights reserved.

\section{Introduction}

The old-fashioned electricity generation scenario has been changing considering that most part of its conventional generation results in pollutant processes, and consequently it causes risks and impacts to the environment and humans. The new generation scenario is been modified as it uses alternative and renewable electrical energy sources with the distributed generation (DG) concept next to the consumption centers, integrating sources such as photovoltaic, wind, fuel cell, and other with the conventional distribution utility grid [1-4]. In 2035, considering the population increasing and the industrial sector expanding, mainly in the development country, the global electrical energy consumption is estimated to be increased more than 50\% compared to 2008 [5].

\footnotetext{
* Corresponding author.

E-mail addresses: sampaio@utfpr.edu (L.P. Sampaio), canesin@dee.feis.unesp.br (C.A. Canesin).
}

In this context, the distributed generation is becoming increasingly highlighted in the world with the purpose to integrate the renewable electrical energy sources into the traditional electrical power distribution grid $[3,4,6]$.

Conventionally, the energy sources used in the DG are connected to a DC-bus, while utility grids work with alternated current (AC). In this context, to connect this kind of energies into the grid it is necessary to use power electronic converters, which are, usually, applied to step-up the alternative energies voltage, to perform the DC to AC conversion and for synchronization to the utility grid. Therefore, the voltage source inverter (VSI) is the most used topology to perform the $\mathrm{DC}-\mathrm{AC}$ conversion. Basically, to achieve connection to the grid it is necessary to filter the harmonic contents to feed a sinusoidal current to the grid; thus, the most common used filters are the L and the LCL filters [6].

Therefore, some related papers propose the VSI current control to perform the active power injection into the utility grid $[8,9]$. Several works propose different control techniques in order to 
operate with uncertain quantities related to the grid parameters and to reduce possible perturbations in the control loops [7-9]. Other papers suggest the VSI voltage control; mainly, when autonomous operation is required and/or a parallelism of the DG is performed. Thus, this operation is usually implemented by means of the droop control technique, in which the frequency control is performed by the active power droop curve and the voltage control is performed using the reactive power droop curve $[6,10,11]$. For optimizing the droop control performance it is possible to use an evolutionary algorithm to determine the best gains used in the active and reactive power curves [12-14]. As the conventional droop control is implemented through a simple droop gain an error is inherent in this control. Therefore, to minimize the error and to improve the transient response it is possible to apply adaptive and improved droop control methodologies to have the accurate voltage and frequency for the DG control [15-17]. In addition, the droop control concept can be used as an auxiliary control to impose the reference values of active and reactive power to the DG, in order to achieve active power injection and reactive power compensation, where these references can also be generated by a supervisory control (remote and/or local) [18].

Consequently, it is common the usage of control techniques applied at power electronics to track a desirable reference, e.g., the VSI output filter voltage needs to follow a sinusoidal reference. With this purpose, the PI and PID controllers are widely employed to control the power electronics converters [19,20], which are designed from the linearized model of the converters obtained by means of small-signal analysis for the operational quiescent point. Sometimes, the converter can operate out of the specified boundary, which can produce undesirable effects and at worst, the system can operate out of the stable region [21,22].

Providing better control results, new power electronics control schemes can handle with system nonlinearities by applying nonlinear control techniques [23]. One of its possible application is to find a better linear approximation model around one operation quiescent point, attenuating those system nonlinearities, dealing with uncertain models and working in wide operation range [7,24].

The feedback linearization is a control technique used to obtain a linearized model from the nonlinear systems by means of the feedback states [23-25]. This approach seeks to minimize the nonlinearity main effects that is present in the system to be controlled, due to exact state transformation and through feedback, this technique is usually better than the conventional approach used to obtain the linearized converter model. On the other hand, the drawback of this technique is the parameter sensitivity involved in the linearization process, which may prevent the exact compensation of possible nonlinearity presents in the system [23].
Recently, researches have been proposed the linear matrix inequalities (LMI) as a better solution to control several applications. In order to guarantee the system robustness, the LMI techniques can be applied to reject or minimize system perturbations, achieving best controllers in a multi-objective problem working even with polytopic uncertainties [26-28].

The LMI constraints together with the D-Stability criteria are powerful tools to be applied in pole placement designs for feedback systems. These techniques can be used to guarantee the system performance, placing the poles in a complex s-plane defined region for the closed-loop system with the purpose to ensure some desirable system dynamic behavior, e.g., overshoot, settling time, transient response and less oscillations. The pole placement is ensured by means of the minimum decay rate, minimum damping ratio and maximum undamped natural frequency, which is used to delimit a maximum time to the vector norm $[18,28]$.

Consequently, this paper proposes a control methodology that uses the LMI constraints in conjunction with D-stability criteria in order to place the poles of the closed-loop system in the complex left-half s-plane region. The linear model used to determine the PI controller gains is obtained by the feedback linearization technique. A three-phase inverter multi-loop control is performed to manage the active and reactive power flow control between distributed generation and the utility grid. In Section 2 the proposed control methodology is presented for each control loop; in Section 3 it is demonstrated the main experimental results and the comparisons between the proposed control and the conventional technique; finally the conclusions and some considerations are described in Section 4.

\section{The proposed control}

It is proposed to control the active power injection and reactive power compensation applied in three-phase system in alternating current low voltage (AC-LV) grid. In this section it is presented the three-phase inverter state-space equations; the feedback linearization technique; the controller design, the LMI constraints and Dstability criteria, and the proposed control techniques applied to the power, voltage and current control loops.

\subsection{Three-phase inverter}

The three-phase inverter control is performed by a multi-loop control based on power, voltage and current control loops, where all compensators are determined using feedback linearization with LMI constraints and based on D-stability criteria. Fig. 1 shows the

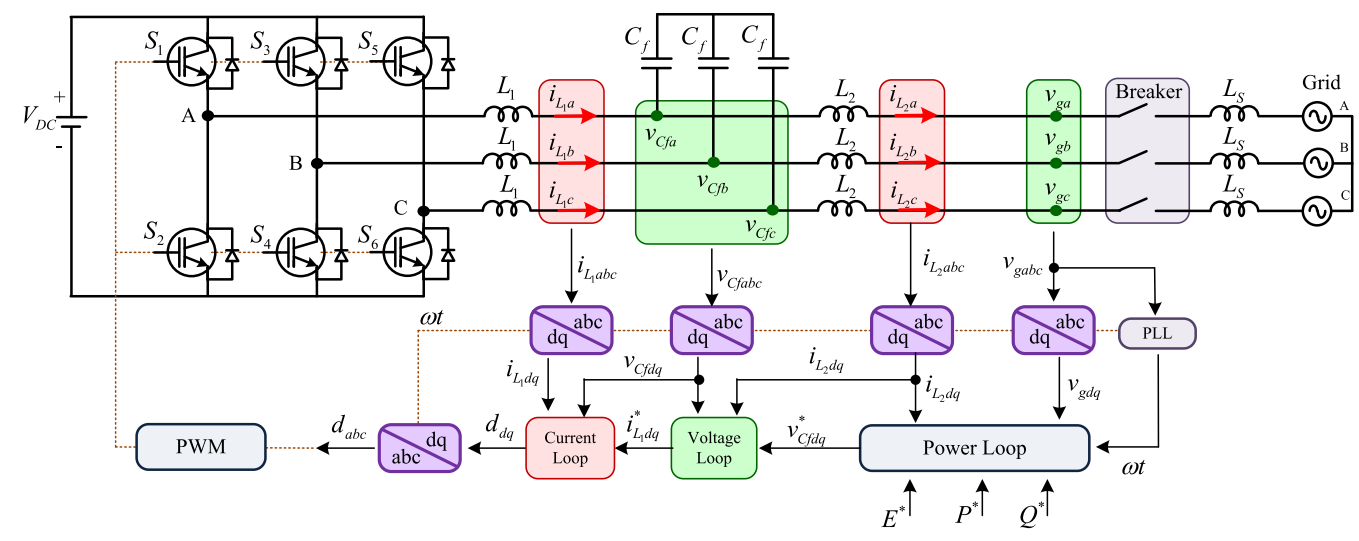

Fig. 1. Proposed control technique applied to grid-tie three-phase inverter with LCL filter. 
proposed grid-connected three-phase inverter control, where the main $a b c$ state-space equations were transformed into $d q$ coordinates.

The main state-space equations that represent the three-phase control in $d q$ coordinates can be expressed as follows:

$L_{1} \frac{d}{d t}\left[\begin{array}{l}i_{L_{1} d} \\ i_{L_{1} q}\end{array}\right]=\left[\begin{array}{l}d_{d} V_{D C} \\ d_{q} V_{D C}\end{array}\right]-\left[\begin{array}{l}v_{C f d} \\ v_{C f q}\end{array}\right]-\frac{3}{2} \omega L_{1}\left[\begin{array}{c}-i_{L_{1} q} \\ i_{L_{1} d}\end{array}\right]$,

$C_{f} \frac{d}{d t}\left[\begin{array}{l}v_{C f d} \\ v_{C f q}\end{array}\right]=\left[\begin{array}{l}i_{L_{1} d} \\ i_{L_{1} q}\end{array}\right]-\left[\begin{array}{l}i_{L_{2} d} \\ i_{L_{2} q}\end{array}\right]-\frac{3}{2} \omega C_{f}\left[\begin{array}{c}-v_{C f q} \\ v_{C f d}\end{array}\right]$,

$L_{2} \frac{d}{d t}\left[\begin{array}{l}i_{L_{2} d} \\ i_{L_{2} q}\end{array}\right]=\left[\begin{array}{l}V_{C f d} \\ V_{C f q}\end{array}\right]-\left[\begin{array}{c}V_{g d} \\ V_{g q}\end{array}\right]-\frac{3}{2} \omega L_{2}\left[\begin{array}{c}-i_{L_{2} q} \\ i_{L_{2} d}\end{array}\right]$

\subsection{Feedback linearization}

A nonlinear system [23] can be represented using the smooth and nonlinear function, as:

$\left\{\begin{array}{l}\dot{x}=f(x)+g(x) u \\ y=h(x)\end{array}\right.$

The control technique applied in this work uses the feedback linearization [25] once the input state $u$ is not directly observed in the output state $y$. The main idea is to transform the nonlinear system into a fully or a partially linear system. It is obtained by differentiating the output state until the input state $u$ appear in the $y^{r}$, derivative of $y$, thus, the derivate of output $y$ (4) can be described as:

$y^{r}=L_{f}^{r} h(x)+L_{g} L_{f}^{r-1} h(x) u$.

If $L_{g} L_{f}^{r-1} h(x) \neq 0$ for some value when $x=x_{0}$ of $\Omega_{\chi}$, also it is verified in the finite neighborhood of $\Omega$ in $\mathrm{x}$, the input state vector can be rewritten as:

$u=\frac{\left[-L_{f}^{r} h(x)+z\right]}{L_{g} L_{f}^{r-1} h(x)}$.

where $\mathrm{z}$ represents the linearized term of the derivative output $y$ and can be derived as:

$y^{r}=z$

\subsection{Controller design}

The state-space representation of a linear and time-invariant system (LTI) can be expressed as:

$\dot{x}=A x+B u$,

$y=C x$.

Concerning closed-loop linear systems and invariant-time domain, the main system is described as (9) when applying feedback matrix $\mathrm{K}$ :

$\dot{x}=(A-B K) x$.

The dynamic error presented in (7) is linearized and a linear controller can be designed into a specified region. Thus, several solutions are possible to be implemented, and one possible solution is the Proportional-Integral (PI) controller usage, considering the three-phase inverter measured variable values in $d q$ coordinates for the fundamental frequency are DC values, the PI controller is an efficient and reliable solution to track the desired reference [23]. Therefore, the linear system $z$ can be represented as:

$z=K_{p} e+K_{i} \int e d t$

The proportional and integral gains must be greater than zero, e.g., $K_{p}>0$ and $K_{i}>0$. It allows (10) to be expressed as:

$\dot{e}=-K_{p} e-K_{i} w$,

where:

$w=\int e d t$

The state-feedback matrix K can be obtained rewriting (11) and (12) into (9), as given as:

$\left[\begin{array}{c}\dot{e} \\ \dot{w}\end{array}\right]=(A-B K)\left[\begin{array}{c}e \\ w\end{array}\right]$

where:

$A=\left[\begin{array}{ll}0 & 0 \\ 1 & 0\end{array}\right], B=\left[\begin{array}{l}1 \\ 0\end{array}\right], K=\left[\begin{array}{ll}K_{p} & K_{i}\end{array}\right]$

\subsection{LMI and D-stability}

The Linear Matrix Inequalities engaged in the solution of convex optimization problems are gaining even more attention due to several applications and great scope in the LMI usage. One of these applications is the pole placement (well-known as DStability) for closed-loop systems into the specified region of the complex s-plane, as shown in Fig. 2. Table 1 illustrates the designated parameters for region $S(\gamma, \sigma, \tau, \theta)$, to place the poles in the closed-loop systems.

Generally, D-stability has the purpose to find the state-feedback controllers $K$ placing the poles (9) in a previously specified $S(\gamma, \sigma, \tau$, $\theta)$ region in the left-half s-plane [26-28]. The main LMIs to solve the problem are defined as [7-9,18,26-28]:

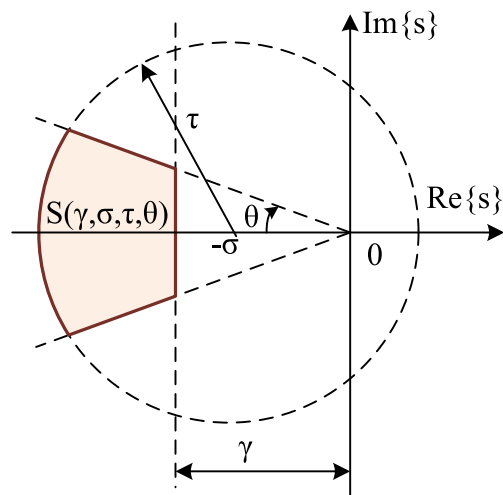

Fig. 2. Region $S(\gamma, \sigma, \tau, \theta)$ for pole placement for a closed-loop system. 
Table 1

Parameters description for region $\mathrm{S}(\gamma, \sigma, \tau, \theta)$

\begin{tabular}{ll}
\hline Parameters & Description \\
\hline$\theta$ & $\begin{array}{l}\text { Boundary for imaginary poles part. It is related to overshoot } \\
\text { and transient response system. }\end{array}$ \\
$\gamma$ & $\begin{array}{l}\text { Lower bound for placed poles module. It defines the settling time. } \\
\sigma, \tau\end{array}$ \\
& $\begin{array}{l}\text { Establish the upper bound for poles module. It defines the } \\
\text { controllers gain. }\end{array}$ \\
\hline
\end{tabular}

$$
\begin{gathered}
U>0, \\
A U+U A^{T}-B Y-Y^{T} B^{T}+2 \gamma U<0, \\
{\left[\begin{array}{cc}
-\tau U & A U-B Y+\sigma U \\
U A^{T}-Y^{T} B^{T}+\sigma U & -\tau U
\end{array}\right]<0,} \\
{\left[\begin{array}{c}
\sin (\theta)\left(A U+U A^{T}-B Y-Y^{T} B^{T}\right) \cos (\theta)\left(A U-U A^{T}-B Y+Y^{T} B^{T}\right) \\
\cos (\theta)\left(U A^{T}-A U+B Y-Y^{T} B^{T}\right) \sin (\theta)\left(U A^{T}+A U-B Y-Y^{T} B^{T}\right)
\end{array}\right]<0 .}
\end{gathered}
$$

If (15) is feasible, then a state feedback $u=-K x$, is stabilized to place the poles in the closed-loop region $S(\gamma, \sigma, \tau, \theta)$ if and only if there is a symmetric matrix $U$ and a matrix $Y$ such that a controller for such state feedback is given by $K=Y U^{-1}$.

\subsection{Power control loop}

The proposed control of the power flow applied in the power control loop uses the well-know expressions for active and reactive power transfer (16)-(17) [6,10-17], where active power is mainly related to the power transfer angle and reactive power is mainly related with voltage magnitude.

$P=\frac{V_{C f_{R M S}} V_{g_{R M S}}}{X_{L_{2}}} \sin (\delta)$,

$Q=\frac{V_{C f_{R M S}} V_{g_{R M S}}}{X_{L_{2}}} \cos (\delta)-\frac{V_{g_{R M S}}^{2}}{X_{L_{2}}}$.

Concerning that the power transfer angle is small, the active and reactive power exhibited in (16) and (17) can be simplified as:

$P=\frac{V_{C f_{R M S}} V_{g_{R M S}}}{X_{L_{2}}} \delta$

$Q=\frac{V_{C f_{R M S}} V_{g_{R M S}}}{X_{L_{2}}}-\frac{V_{g_{R M S}}^{2}}{X_{L_{2}}}$

Therefore, the voltage reference for the voltage control loop can be generated by means of power loop as:

$v_{C f d}^{*}=V_{C f_{R M S}} \cos (\delta)$,

$v_{C f q}^{*}=V_{C f_{R M S}} \sin (\delta)$.

The error in the active power control loop can be obtained by:

$e_{P}=P^{*}-P$.

Deriving (22), replacing (18) and linearizing the system, the power transfer angle can be expressed as:
$\delta=\frac{1}{V_{C_{R M S}}} \int z_{P} d t$

where:

$\dot{e}_{P}=-\frac{z_{P} V_{g_{R M S}}}{X_{L_{2}}}$

Rearranging (24) in order to use a PI controller (11)-(13), the matrices for the active power control loop is given by:

$A=\left[\begin{array}{ll}0 & 0 \\ 1 & 0\end{array}\right], B=\left[\begin{array}{c}\frac{V_{g_{R M S}}}{X_{L_{2}}} \\ 0\end{array}\right], K=\left[\begin{array}{ll}K_{p p} & K_{i p}\end{array}\right]$.

The error in the reactive power control loop can be expressed as:

$e_{Q}=Q^{*}-Q$.

Deriving (26), replacing (19) and linearizing the system, the voltage reference can be given by:

$V_{C f_{R M S}}=\int z_{Q} d t$

where:

$\dot{e}_{Q}=-\frac{z_{Q} V_{g_{R M S}}}{X_{L_{2}}}$.

Finally, expressing (28) in order to use a PI controller (11)-(13), the matrices for the reactive power control loop can be expressed as:

$A=\left[\begin{array}{ll}0 & 0 \\ 1 & 0\end{array}\right], B=\left[\begin{array}{c}\frac{V_{g_{R M S}}}{X_{L_{2}}} \\ 0\end{array}\right], K=\left[\begin{array}{ll}K_{p q} & K_{i q}\end{array}\right]$.

In order to improve the power control loop dynamics the RMS voltage value across the capacitor $C_{f}\left(V_{C f_{R M S}}\right)$ presented in (20), (21) and (23) is calculated as:

$V_{C f_{R M S}}=\left(E^{*}+\Delta V_{C}\right)$.

where $E^{*}$ is the RMS value of the grid voltage (phase-neutral), in this case $127 \mathrm{~V}, \Delta V_{C}$ is the voltage deviation necessary to compensate the reactive power into the grid; thus, equation (27) was modified to improve the output voltage calculus (31). It was considered that the system operates only grid-connected. So for improving the power control loop system dynamic response the $V_{g_{R M S}}$ can be regarded as a constant value (e.g., $127 \mathrm{~V})$.

$\Delta V_{C}=\int z_{Q} d t$

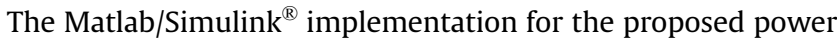
control loop used for voltage reference generation is depicted at Fig. 3.

\subsection{Voltage control loop}

The voltage loop provides the current reference for the current control loop. This loop bandwidth must be greater than the grid frequency and lower than the current control loop bandwidth, otherwise the output voltage can be distorted or the voltage control loop may interfere in the current control loop dynamics. This loop aimed to track the voltage references $v_{C f d}^{*}$ and $v_{C f q}^{*}$, across $C_{f}$ 


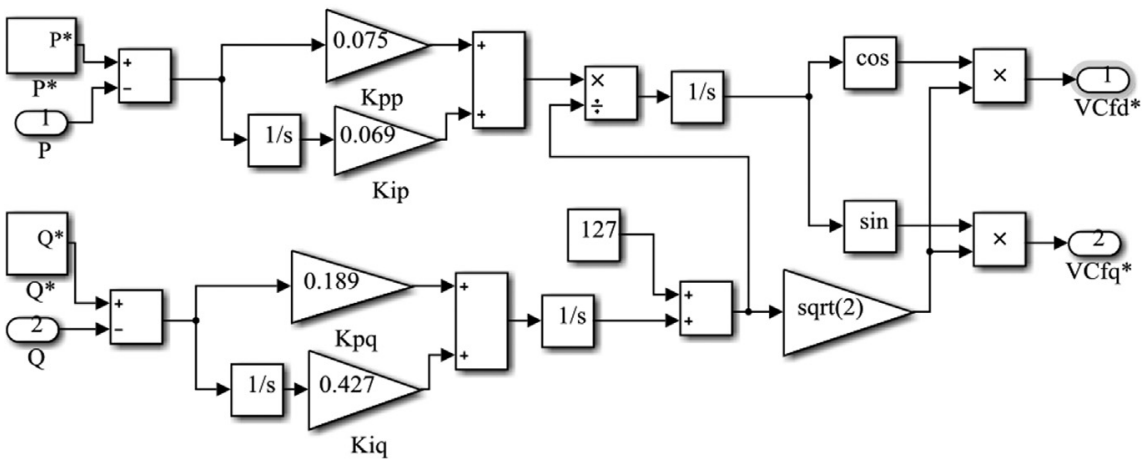

Fig. 3. Power Loop implementation in Matlab/Simulink ${ }^{\circledR}$.

capacitors. Therefore, this loop error can be expressed as (32).

$\left[\begin{array}{l}e_{V d} \\ e_{V q}\end{array}\right]=\left[\begin{array}{l}v_{C f d}^{*} \\ v_{C f q}^{*}\end{array}\right]-\left[\begin{array}{l}v_{C f d} \\ v_{C f q}\end{array}\right]$.

Deriving (32), replacing (2) and linearizing the system, the current reference can be expressed as:

$\left[\begin{array}{l}i_{L_{1} d}^{*} \\ i_{L_{1} q}^{*}\end{array}\right]=\left[\begin{array}{c}z_{V d} \\ z_{V q}\end{array}\right]+\left[\begin{array}{c}i_{L_{2} d} \\ i_{L_{2} q}\end{array}\right]+\frac{3}{2} \omega C_{f}\left[\begin{array}{c}-v_{C f q} \\ v_{C f d}\end{array}\right]$,

where:

$\left[\begin{array}{c}z_{V d} \\ z_{V q}\end{array}\right]=-C_{f}\left[\begin{array}{l}\dot{e}_{V d} \\ \dot{e}_{V q}\end{array}\right]$

Reorganizing (34) in order to use a PI controller (11)-(13), the matrices for the voltage loop for both direct and quadrature axes are given by (35).

$A=\left[\begin{array}{ll}0 & 0 \\ 1 & 0\end{array}\right], \quad B=\left[\begin{array}{c}\frac{1}{C_{f}} \\ 0\end{array}\right], \quad K=\left[\begin{array}{ll}K_{p v} & K_{i v}\end{array}\right]$

The Matlab/Simulink ${ }^{\circledR}$ proposed voltage control loop implementation used for current reference generation is demonstrate at Fig. 4.

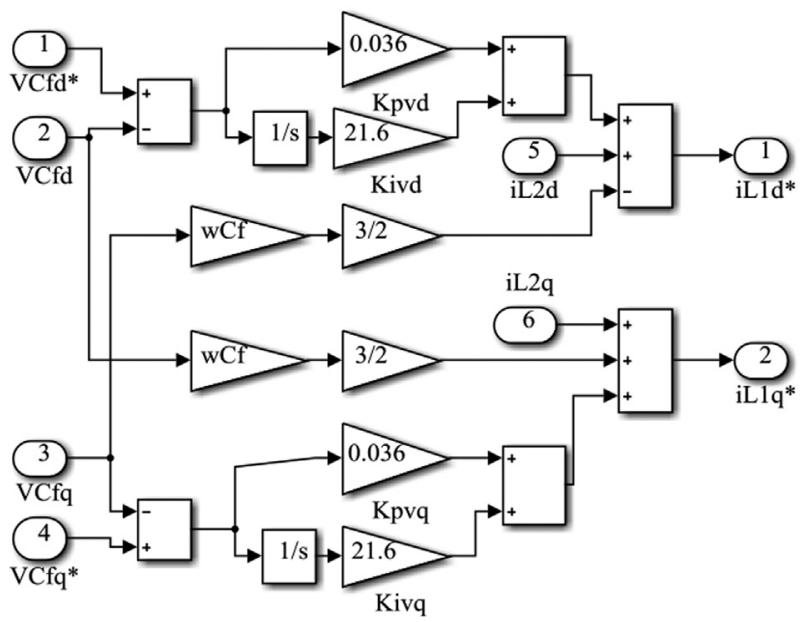

Fig. 4. Voltage Control Loop implemented in Matlab/Simulink ${ }^{(\mathbb{R}}$.

\subsection{Current control loop}

The current control loop provides the signal for the three-phase PWM modulation and it is required to be the fastest loop in the system. The error between the current through the inductor $L_{1 d q}$ and the current reference $i_{L_{1} d q}^{*}$ is given by:

$\left[\begin{array}{l}e_{i d} \\ e_{i q}\end{array}\right]=\left[\begin{array}{l}i_{L_{1} d}^{*} \\ i_{L_{1} q}^{*}\end{array}\right]-\left[\begin{array}{l}i_{L_{1} d} \\ i_{L_{1} q}\end{array}\right]$.

As the current control loop has the objective to determine the VSI modulation, which it is not clearly shown in (36), the feedback linearization is applied until the modulation be clearly determined. In sequence, expression (1) was replaced into the linearization process in order to obtain the VSI modulation, as:

$\left[\begin{array}{l}d_{d} \\ d_{q}\end{array}\right]=\frac{1}{V_{D C}}\left[\begin{array}{l}z_{i d} \\ z_{i q}\end{array}\right]+\frac{1}{V_{D C}}\left[\begin{array}{l}v_{C f d} \\ v_{C f q}\end{array}\right]+\frac{3}{2} \frac{\omega L_{1}}{V_{D C}}\left[\begin{array}{c}-i_{L_{1} q} \\ i_{L_{1} d}\end{array}\right]$

where:

$\left[\begin{array}{c}z_{i d} \\ z_{i q}\end{array}\right]=-L_{1}\left[\begin{array}{c}\dot{e}_{i d} \\ \dot{e}_{i q}\end{array}\right]$

Thus, reorganizing (38) in order to use a PI controller (11)-(13), the matrices for the current loop for both direct and quadrature axes are given by (39).

$A=\left[\begin{array}{ll}0 & 0 \\ 1 & 0\end{array}\right], \quad B=\left[\begin{array}{c}1 \\ L_{1} \\ 0\end{array}\right], K=\left[\begin{array}{ll}K_{p i} & K_{i i}\end{array}\right]$.

The Matlab/Simulink ${ }^{\circledR}$ proposed current control loop implementation used for the obtainment of the VSI modulation is demonstrate at Fig. 5.

Therefore, by means of the LMI presented in (15) it is possible to determine the PI controllers gains for the power, voltage and current control loops, introducing the matrices (25), (29), (35) and (39) in (15), in order to obtain the state-feedback controllers obtained from feedback linearization.

\section{Results}

The proposed control was implemented experimentally to demonstrate its feasibility, where the power flow control is applied for a grid-tied three-phase inverter with LCL filter, using nonlinear and robust control. The main parameters used for the three-phase inverter are summarized in Table 2.

The control laws were implemented by means of the DSPACE 


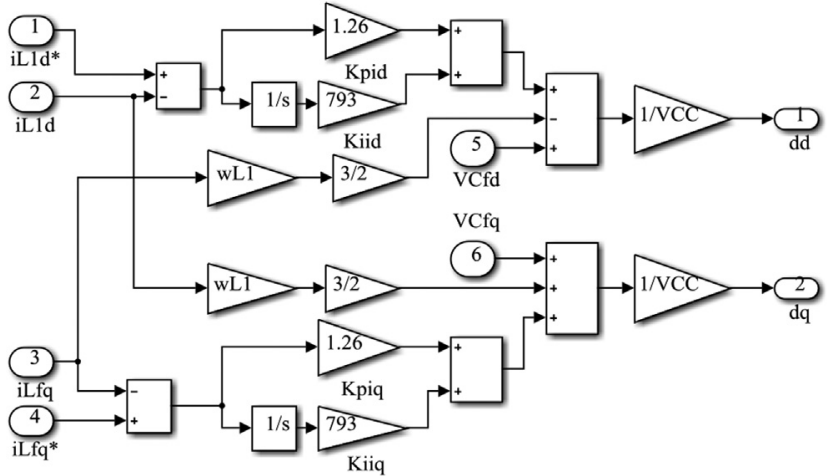

Fig. 5. Current Control Loop implemented in Matlab/Simulink ${ }^{\circledR}$.

Table 2

Three-phase design parameters.

\begin{tabular}{ll}
\hline Parameters & Values \\
\hline DC input voltage (average) & $V_{D C}=450 \mathrm{~V}$ \\
Grid phase-neutral voltage (rms) & $V g=127 \mathrm{~V}$ \\
Nominal output power & $3000 \mathrm{VA}$ \\
Switching frequency & $f_{s}=16 \mathrm{kHz}$ \\
Inductor $L_{1}$ & $L_{1}=0.5 \mathrm{mH}$ \\
Inductor $L_{2}$ & $L_{2}=7 \mathrm{mH}$ \\
Capacitor $C$ & $C_{f}=15 \mu \mathrm{F}$ \\
\hline
\end{tabular}

Table 3

Design of the proposed controller applied for the three-phase inverter.

\begin{tabular}{|c|c|c|c|c|c|c|}
\hline \multirow[t]{2}{*}{ Loop } & \multicolumn{4}{|c|}{ Parameters for $S(\gamma, \sigma, \tau, \theta)$ region } & \multicolumn{2}{|c|}{ PI - controller } \\
\hline & $\gamma$ & $\sigma$ & $\tau$ & $\theta$ & $K_{p}$ & $K_{i}$ \\
\hline Active power & 1.8 & 0 & 1.83 & $2^{\circ}$ & 0.075 & 0.069 \\
\hline Reactive power & 4.5 & 0 & 4.568 & $0.02^{\circ}$ & 0.189 & 0.427 \\
\hline Voltage $(d q)$ & 1200 & 0 & 1201 & $1^{\circ}$ & 0.036 & 21.6 \\
\hline Current $(d q)$ & 1200 & 0 & 1320 & $2^{\circ}$ & 1.260 & 792.98 \\
\hline
\end{tabular}

ACE1104 digital platform with sampling frequency of $10 \mathrm{kHz}$. The grid emulator was performed using California MX45-3Pi and the DC voltage was supplied by Tectrol along with a Boost converter.

The controller gains were determined in Matlab ${ }^{\circledR}$ with YALMIP toolbox, using SEDUMI [29] solver. The parameter $\gamma$ is well-known in literature as decay rate $[18,28]$. This parameter is inserted into LMIs restriction to ensure the maximum establishment time for the vector states norm and it is given by (40). Where $x$ is the state vector; thus, the time establishment can be defined by (41). The parameters used to determine the $S(\gamma, \sigma, \tau, \theta)$ region in the left-half$s$-plane and the controller gains obtained for the PI compensator are illustrated in Table 3.

$\lim _{t_{e} \rightarrow \infty} e^{-\gamma t_{e}}\|x\|=0$

$t_{e}=\frac{2 \pi}{\gamma} \approx \frac{6}{\gamma}$

Fig. 6 shows the Graphic User Interface (GUI). It is a friendly-user interface that allows easy management and active power injection and reactive power compensation control. The GUI was developed using the Control Desk (Dspace ${ }^{\circledR}$ Software Kit) environment. From this interface it is possible to control the amount of power to be injected to the grid ( $\mathrm{P}$ and $\mathrm{Q}$ ) and also the main voltages and currents can be monitored in real time.

\subsection{Results for normal grid operation}

Figs. 7 and 8 show the active and reactive power flow tracking, where the power flow was transferred in fast way and one can observe that the proposed control allows fast dynamic responses and the error in steady state is near to zero.

Some step power changes in the power references were applied as verified at Figs. 7 and 8. The settling time for the power loop was about $1 \mathrm{~s}$, i.e to set new power transfer values. As it can be noted the

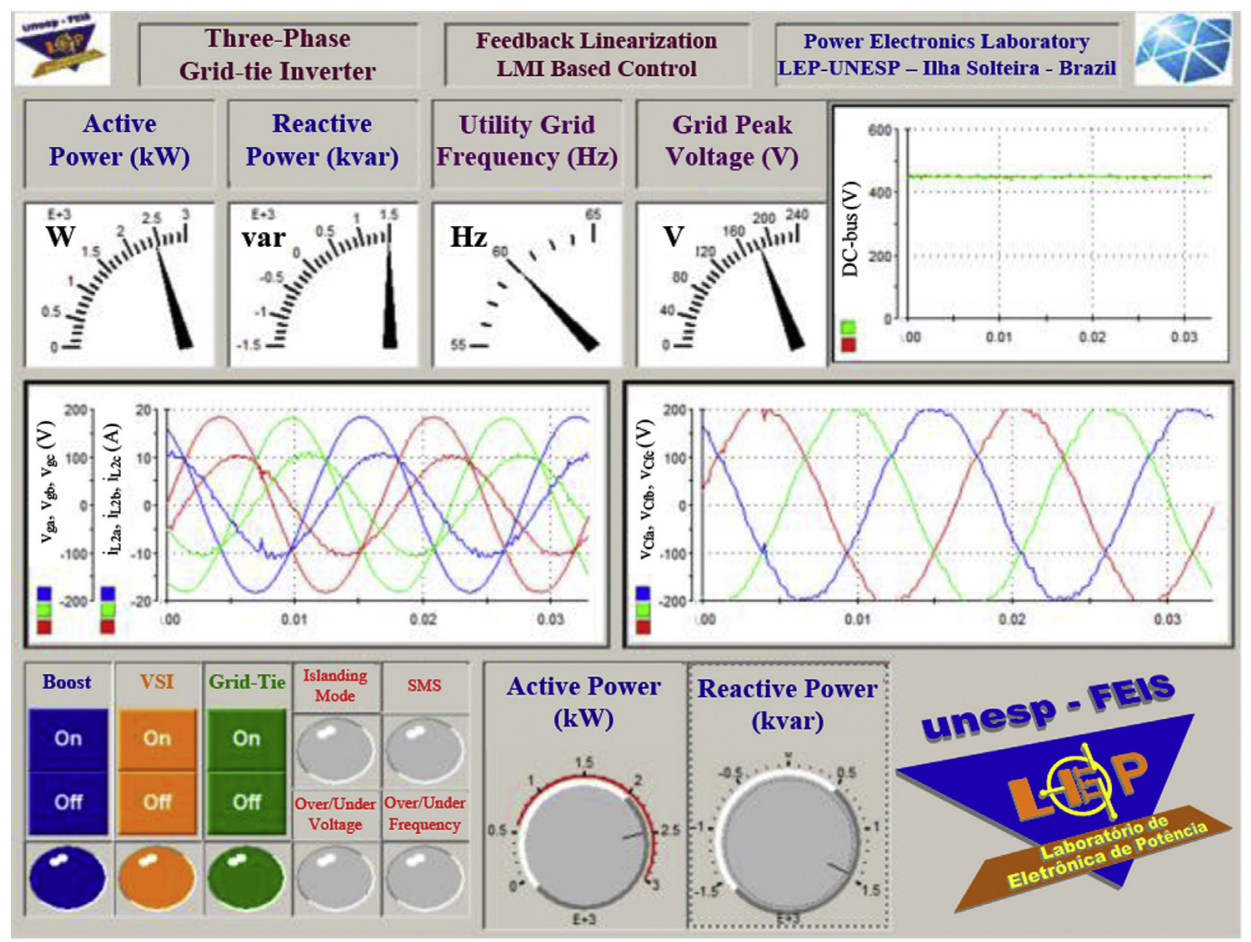

Fig. 6. GUI for Active and reactive power flow control. 


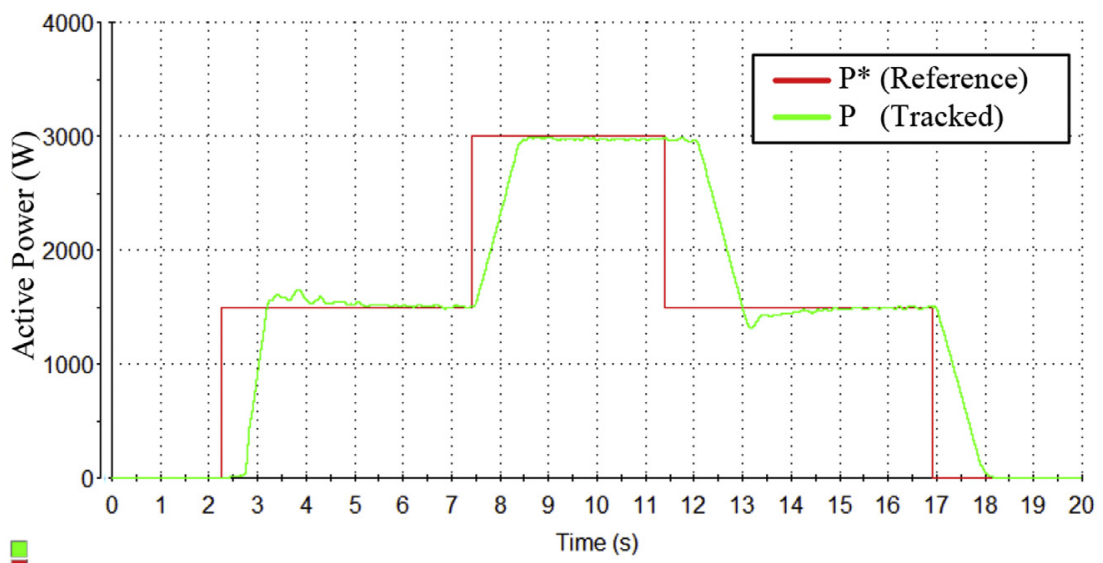

Fig. 7. Active power tracking.

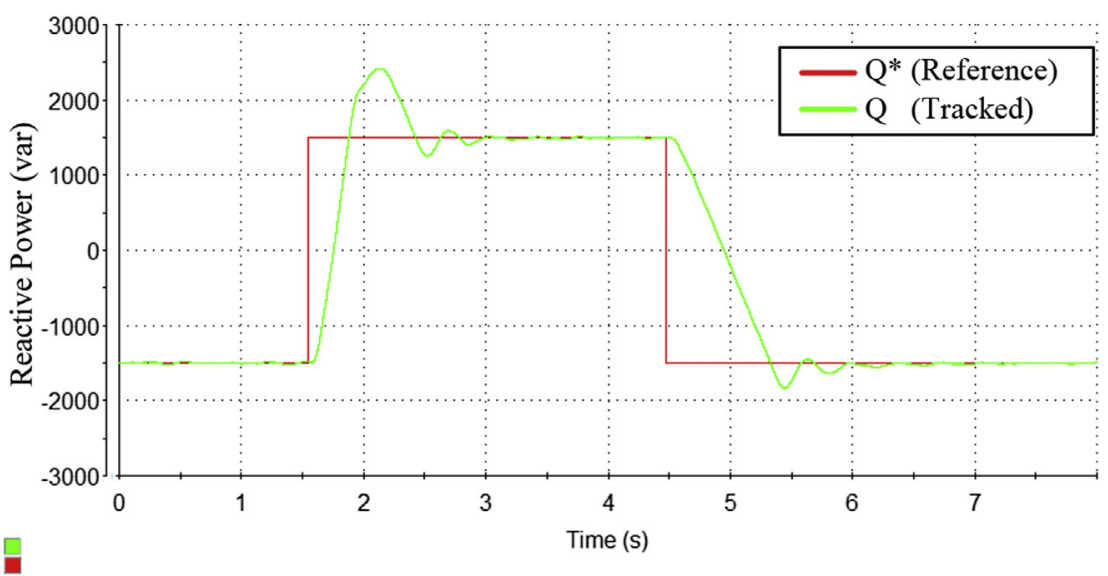

Fig. 8. Reactive power tracking.

D-stability region should be adjusted so that the system operates within acceptable patterns from the utility grid, considering a scenario in which the DG must inject active and reactive power in a fast way, to guarantee the power quality, the proposed control allows a good relationship between speed and overshoot.

Fig. 9 shows the grid voltage and current injection into the grid for nominal power $(3000 \mathrm{~W})(1 \mathrm{~kW}$ per phase). It can be observed the THD is much lower than $5 \%$, the maximum value allowed by IEEE standard [30].

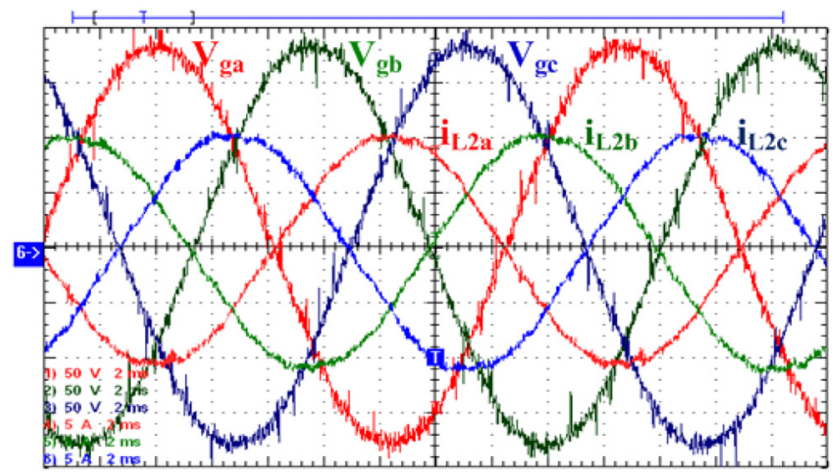

Fig. 9. Grid Voltage and current injection into the grid for nominal power. $\mathrm{Vg}$ : $50 \mathrm{~V} /$ div; $i_{\mathrm{L} 2}: 5 \mathrm{~A} /$ div; time: $2 \mathrm{~ms} /$ div. $\operatorname{THDi}_{L_{2} a}: 2.1 \%$; $\operatorname{THDi}_{L_{2} b}: 2.1 \% \operatorname{THDi}_{L_{2} c}: 2.3 \%$.
The harmonic distortion on the injected grid current, considering Fig. 9 scenario, is presented at Fig. 10. As it can be seen all three-phase harmonic contents are in compliance with IEEE standard [30].

Fig. 11 shows the grid voltage and current injection into the grid for active power injection of $1500 \mathrm{~W}$ and reactive power compensation of +1500 var. Fig. 12 shows the grid voltage and current injection into the grid for active power injection of $1500 \mathrm{~W}$ and reactive power compensation of -1500 var. The apparent power was 3000VA for both situations.

\subsection{Results for anti-islanding and protections}

For attending the standards requirements during the islanding mode and grid anomalous operation, the SMS (Slide Mode Frequency Shift) [31] algorithm was used as active method and the over/under voltage and frequency were implemented through passive methods. Fig. 13 shows the SMS algorithm block diagram.

The active power loop modify the power transfer angle in order to track the desired power, thus, naturally the control tries to modify the voltage frequency; nevertheless, in the grid presence the frequency is not modified. As a result, the SMS algorithm was implemented together with the active power loop, with over/under voltage detection. Fig. 14 shows the results of anti-islanding protection. 


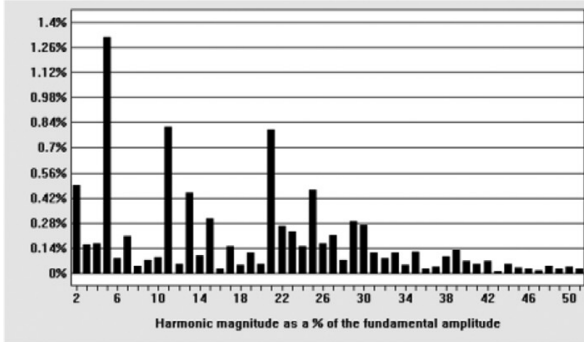

(a) Phase A

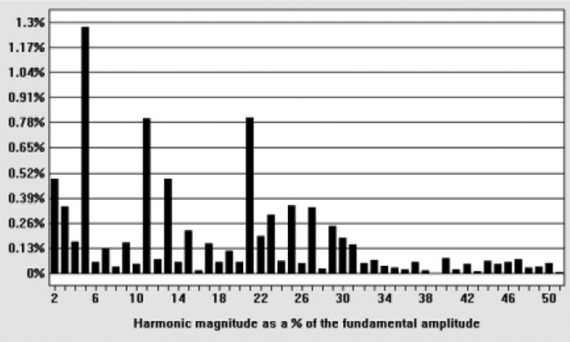

(b) Phase B

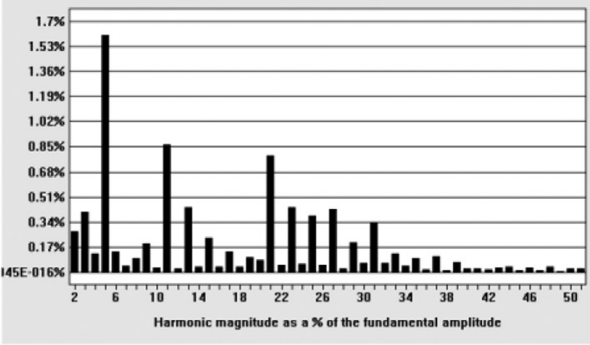

(c) Phase C

Fig. 10. Harmonic Distortion on the Injected Grid Current for Nominal Power $(P=3000 \mathrm{~W}$ e $\mathrm{Q}=0$ var).

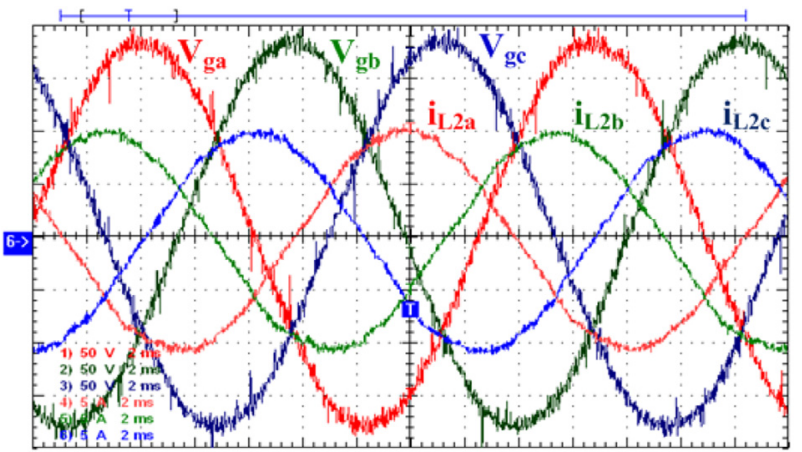

Fig. 11. Grid voltage and current injection into the grid for Active power injection of $1500 \mathrm{~W}$ and reactive power compensation of $1500 \mathrm{var}$. Vg: $50 \mathrm{~V} / \mathrm{div}$; $\mathrm{i}_{\mathrm{L} 2}: 5 \mathrm{~A} / \mathrm{div}$; time: $2 \mathrm{~ms} / \mathrm{div}$.

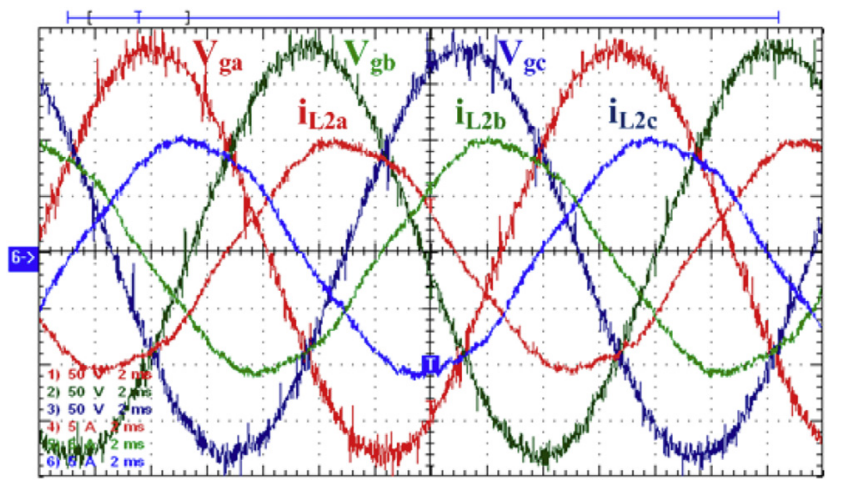

Fig. 12. Grid voltage and current injection into the grid for Active power injection of $1500 \mathrm{~W}$ and reactive power compensation of -1500 var. $\mathrm{Vg}: 50 \mathrm{~V} / \mathrm{div} ; \mathrm{i}_{\mathrm{L} 2}: 5 \mathrm{~A} / \mathrm{div}$; time: $2 \mathrm{~ms} / \mathrm{div}$.

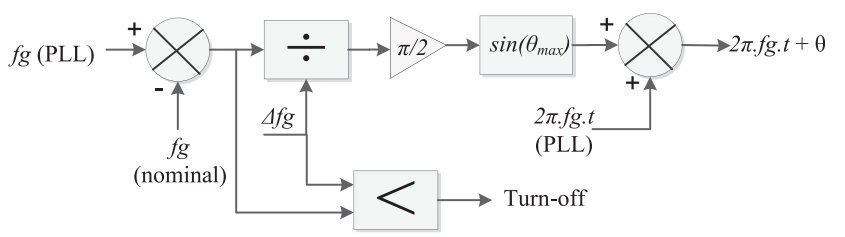

Fig. 13. SMS algorithm block diagram.

The overvoltage and undervoltage protections were implemented using the direct-quadrature grid voltage, in accordance with the voltage limits given by IEC 62116 [32]. Fig. 15 shows the

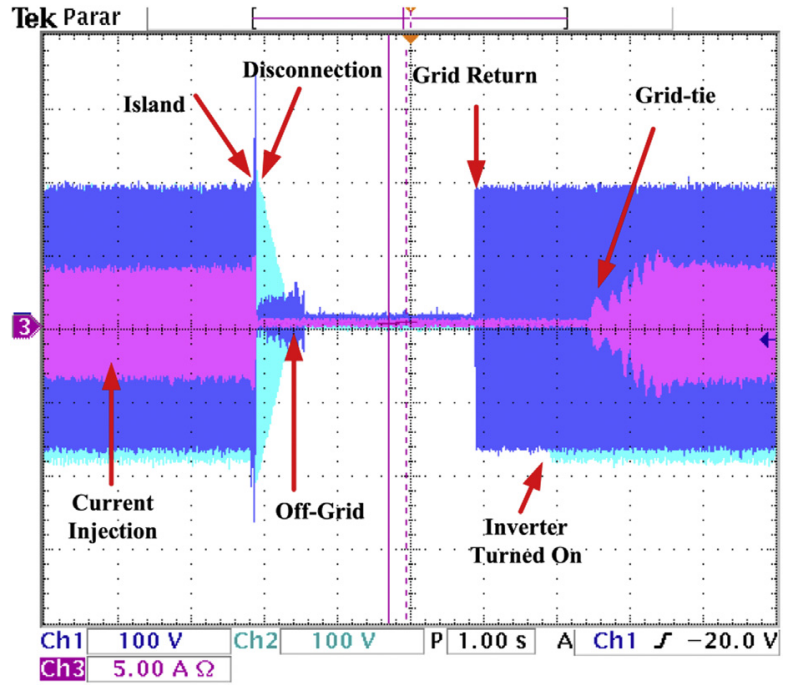

Fig. 14. Islanding protection and reconnection with the grid.

over and under voltage protections.

The protections against overfrequency and underfrequency were implemented by means of the verification of the grid voltage frequency, using the phase-locked loop (PLL) frequency, as shown in Fig. 16. It can be observed that the proposed protections can detect the frequency fault occurrence quickly below the time value defined by the IEC standard [32].

\subsection{Comparisons}

In order to demonstrated the contribution of this proposed work an evaluation was performed, comparing the proposed technique with the conventional VSI with LCL filter control technique. The comparison was performed using Matlab/Simulink ${ }^{\circledR}$ software. Fig. 19 shows the conventional multi-loop control block diagram of the voltage source inverter with LCL filter, which was obtained by means of the small-signal analysis over equations (1)-(3). The gains of the PI compensator showed in Fig. 17 are presented in Table 4.

With the purpose to compare the proposed control scheme effectiveness, both control methods were submitted to the same steps of active and reactive power references. Initially, the active power and reactive power references are defined equal to 0 . From 2 to $10 \mathrm{~s}$ the active power reference is changed to $3000 \mathrm{~W}$ while reactive power reference is kept in 0 var. From 10 to $18 \mathrm{~s}$ the active power reference is changed to $2500 \mathrm{~W}$ and reactive power reference is set up to 1500 var. From 18 until $26 \mathrm{~s}$ the reactive power 


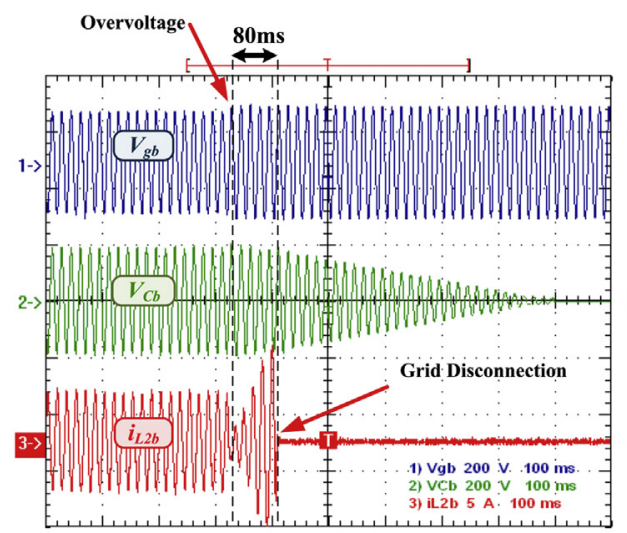

(a)

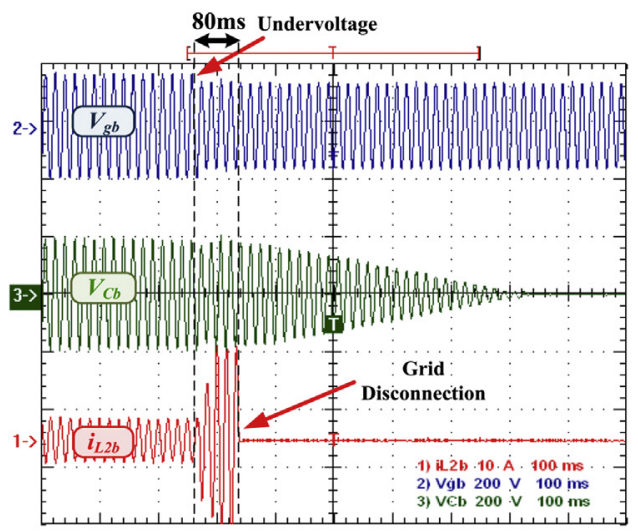

(b)

Fig. 15. Results considering the system safety: (a) Overvoltage protection and (b) Undervoltage protection.

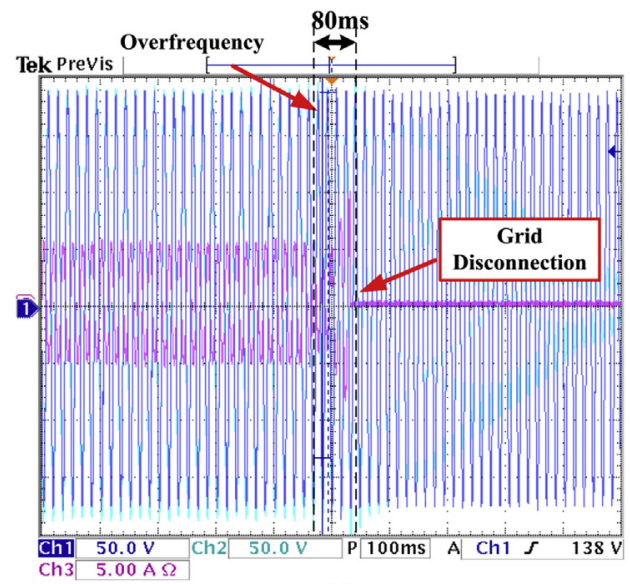

(a)

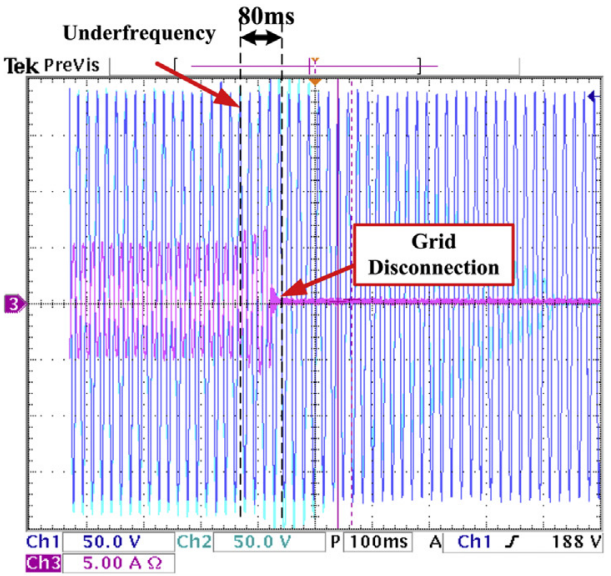

(b)

Fig. 16. Results considering the system safety: (a) Overfrequency protection and (b) Underfrequency protection.

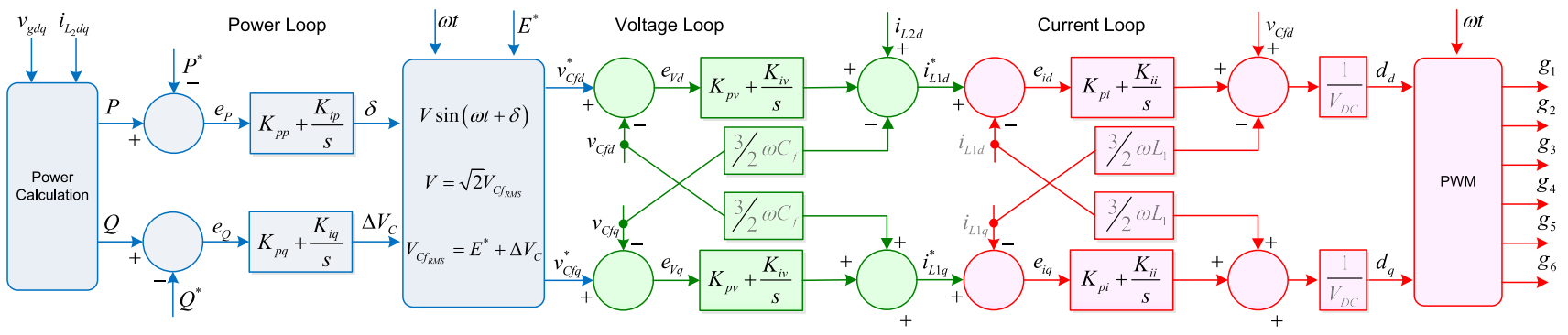

Fig. 17. Block diagram applied in the conventional control of the VSI with LCL filter.

reference is changed to -1500 var while the active power reference is kept constant in 2500 W. These comparisons are shown in Fig. 18.

Comparing the results of Fig. 18, it can be seen that the proposed control operates with minor overshoots and fast responses when compared with the conventional control, both for the active and reactive power loops during reference changes. Considering the active power loop shown in Fig. 18 a, the overshoot for the proposed control was $11.20 \%$ while considering the conventional approach it was about $47 \%$. The proposed control achieved a settling time of $3.0 \mathrm{~s}$ while the conventional reached $4.2 \mathrm{~s}$. For the reactive power loop the overshoot of the proposed control was $37 \%$, and $48 \%$ is achieved for the conventional one. Finally, the settling time for both methodology was $1.0 \mathrm{~s}$, as can be observed in Fig. 18 b.

Fig. 19 shows the behavior of the voltage and current loops for the direct axis considering the changes in the active and reactive power references presented in Fig. 18. As can be observed in Fig. 19 the proposed control can track the voltage reference $v_{C f d}^{*}$ and current reference $i_{L_{1} d}^{*}$ generated by power loop and voltage loop, respectively. Considering the proposed control, the overshoot and settling time were $2.0 \%$ and $0.8 \mathrm{~s}$ for the voltage loop, and $1.0 \%$ and $0.6 \mathrm{~s}$ for the current loop. The conventional control applied in the voltage loop does not track the reference $V_{C f d}^{*}$ appropriately; thus, 


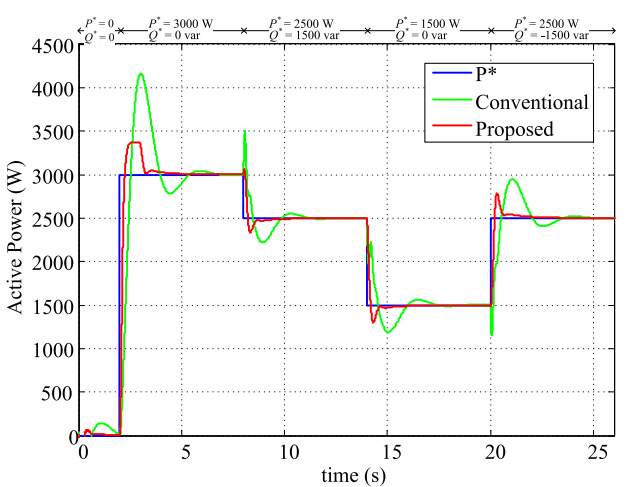

(a) Active Power Loop

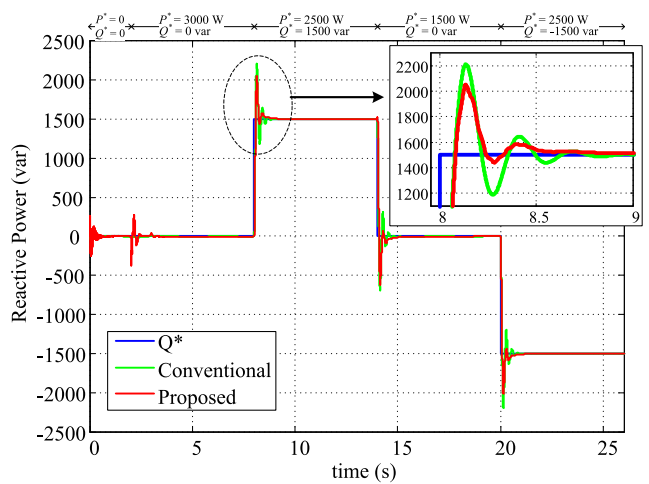

(b) Reactive Power Loop

Fig. 18. Comparison between the proposed control methodology and conventional control during reference changes of active power and reactive power.
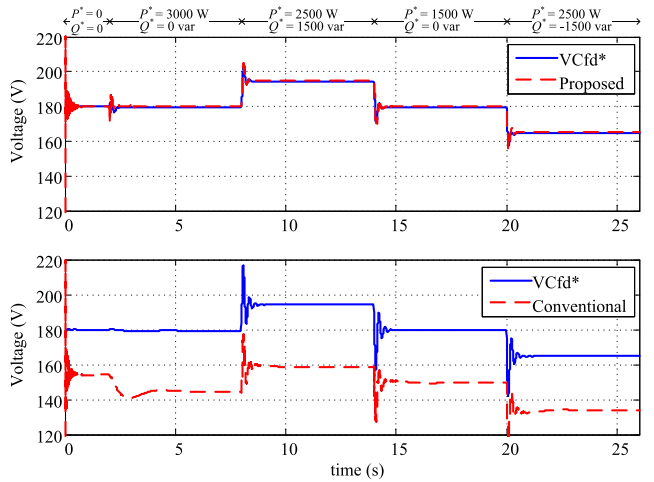

(a) Voltage Loop - direct axis
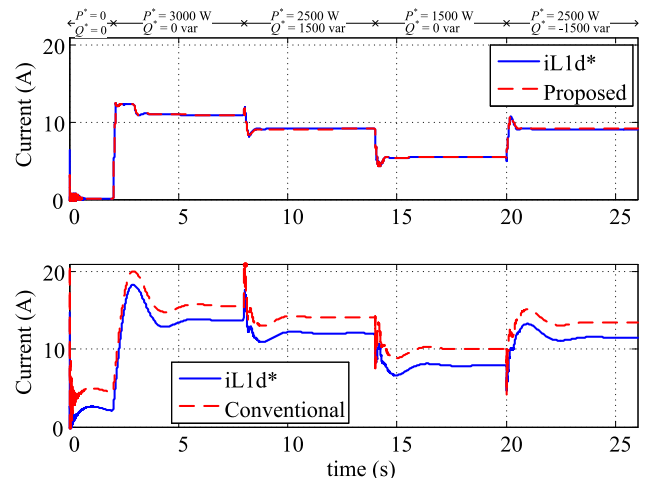

(b) Current Loop - direct axis

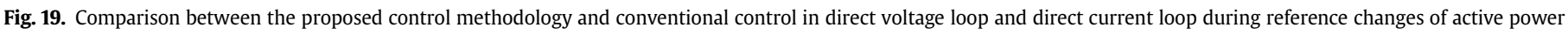
and reactive power.

Table 4

Parameters used in the conventional control of the VSI with LCL filter

\begin{tabular}{|c|c|c|c|c|c|c|c|c|}
\hline & \multicolumn{2}{|c|}{ Active power loop } & \multicolumn{2}{|c|}{$\begin{array}{l}\text { Reactive } \\
\text { power loop }\end{array}$} & \multicolumn{2}{|c|}{ Voltage loop } & \multicolumn{2}{|c|}{ Current loop } \\
\hline & $K_{p p}$ & $K_{i p}$ & $K_{p q}$ & $K_{i q}$ & $K_{p v}$ & $K_{i v}$ & $K_{p i}$ & $K_{i i}$ \\
\hline Gains & 0.00013 & 0.00026 & 0.0018 & 0.392 & 0.0821 & 59.585 & 0.0144 & 52.1411 \\
\hline
\end{tabular}

the voltage loop increases the current reference value $\left(i_{L_{1} d}^{*}\right)$.

Despite the conventional control provides the desired active and reactive power for the system, the proposed control operates with superior performance, mainly, when the comparison is performed in the internal control loops. Therefore, the comparisons demonstrate the proposed control methodology contribution, which operates with fast dynamics and lower overshoot, ensuring the power flow control between the DG and utility grid can be performed within the presented design criteria.

\section{Conclusion}

This paper presented a technique to control the active and reactive power flow between a DG and utility grid through a threephase grid-tie inverter. The proposed technique uses statefeedback controller $\mathrm{K}$ with reduced gains and fast responses in order to track the desirables $P^{*}$ and $Q^{*}$ values, considering a microgrid scenario with DG.
The experimental results demonstrated the proposed control feasibility, which can allow the three-phase inverter operates with fast dynamics, providing current injection into the AC grid with low THD for any relationship between $P^{*}$ and $Q^{*}$. Furthermore, the paper presented experimental results for anti-islanding detection and protections against over/undervoltage and over/underfrequency. These algorithms are extremely important to attend standards, to protect and prevent accidents over connections between the DG and the utility grid, and finally, for the grid workers.

The comparison with a conventional control technique was performed, demonstrating the proposed control benefits once it operates with fast dynamics and lower overshoots when compared with the conventional approach.

The proposed control used a nonlinear control technique wellknown as feedback linearization to attenuate possible disturbances and nonlinearities presents in the system. Furthermore, the controllers were designed by means of the Linear Matrix Inequalities constraints with D-stability criteria, in order to ensure the pole placement in the s-plane specified region. Finally, the proposed control design has the state-feedback benefit that improves the control response and reduces possible interferences and perturbations into the system.

\section{Acknowledgment}

The authors would like to thank FAPESP, CNPq, CAPES and Semikron for financial support given to the development of this work. 


\section{References}

[1] M.A.G. de Brito, L.P. Sampaio, L. Galotto Jr., C.A. Canesin, Evaluation of the main MPPT techniques for photovoltaic applications, IEEE Trans. Ind. Electron. 60 (3) (March 2013) 1156-1167.

[2] A. Consoli, M. Cacciato, V. Crisafulli, Power converters for photovoltaic generation systems in smart grid applications, Eletrônica Potência - SOBRAEP 14 (4) (dezembro 2009) 251-257.

[3] R.F. Arritt, R.C. Dugan, Distribution system analysis and the future smart grid, IEEE Trans. Ind. Appl. 47 (6) (November/December 2011) 2343-2350.

[4] R.H. Lasseter, Smart distribution: coupled microgrids, in: Proc. of IEEE, vol. 99 2011, pp. 1074-1082.

[5] United States Energy Information - Us Eia. Annual Energy Outlook 2011. Washington-DC, 2011. Avaliable from, http://www.eia.gov (accessed April 2015).

[6] A. Llaria, O. Curea, J. Jiménez, H. Camblong, Survey on microgrids: unplanned islanding and related inverter control techniques, Renew. Energy 36 (8) (August 2011) 2052-2061.

[7] D. Lalili, A. Mellit, N. Lourci, B. Medjahed, E.M. Berkouk, Input output feedback linearization control and variable step size MPPT algorithm of a gridconnected photovoltaic inverter, Renew. Energy 36 (12) (December 2011) 3282-3291.

[8] L.A. Maccari, J.R. Massing, L. Schuch, C. Rech, H. Pinheiro, R.C.L.F. Oliveira, V.F. Montagner, LMI-based control for grid-connected converters with LCL filters under uncertain parameters, IEEE Trans. Power Electron. 29 (7) (July 2014) 3776-3785.

[9] J.C.U. Pena, G. Melo, C.A. Canesin, L.P. Sampaio, Robust control of a singlephase VSI with LCL filter for grid-tie and islanded operation modes applied to PV distributed generation in microgrids environment, in: Proc. of ECCE, September 2014, pp. 785-792.

[10] A. Samadi, E. Shayesteh, R. Eriksson, B. Rawn, L. Söder, Multi-objective coordinated droop-based voltage regulation in distribution grids with PV systems, Renew. Energy, 71 (November 2014) 315-323.

[11] K. Rouzbehi, A. Miranian, J.I. Candela, A. Luna, P. Rodriguez, A generalized voltage droop strategy for control of multiterminal DC grids, IEEE Trans. Ind. Appl. 51 (1) (Jan.-Feb. 2015) 607-618.

[12] R.B. Godoy, C.A. Canesin, J.O.P. Pinto, A.M.A.C. Pinto, E.A.A. Coelho, Differential evolution based optimization of the dynamic response for parallel operation of inverters with no controllers interconnection, IEEE Trans. Ind. Electron. 59 (7) (July 2012) 2859-2866.

[13] R.B. Godoy, L.A. Carniato, J.O.P. Pinto, C.A. Canesin, R. Cordero, Power flow optimization for grid connected inverter using evolutionary algorithm and additional control loop, in: Proc. of COBEP, 2011, pp. 422-427.

[14] R.B. Godoy, J.O.P. Pinto, C.A. Canesin, Optimized parallelism of two single phase inverters based on evolutionary theory, in: Proc. of SPEEDAM, 2010, pp. 1135-1140.
[15] J.C. Vasquez, J.M. Guerrero, A. Luna, P. Rodriguez, R. Teodorescu, Adaptive droop control applied to voltage-source inverters operating in grid-connected and islanded modes, IEEE Trans. Ind. Electron. 56 (10) (October 2009) 4088-4096.

[16] Hua Han, Yao Liu, Yao Sun, Mei Su, J.M. Guerrero, An improved droop contro strategy for reactive power sharing in islanded microgrid, IEEE Trans. Power Electron. 30 (6) (June 2015) 3133-3141.

[17] S. Eren, M. Pahlevani, A. Bakhshai, P. Jain, An adaptive droop DC-bus voltage controller for a grid-connected voltage source inverter with LCL filter, IEEE Trans. Power Electron. 30 (2) (Feb. 2015) 547-560.

[18] L.P. Sampaio, M.A.G. de Brito, M.G. Alves, G.A. e Melo, C.A. Canesin, Grid-tie three-phase inverter with active and reactive power flow control capability, Proc. COBEP (2013) 1039-1045.

[19] L.P. Sampaio, M.A.G. de Brito, L. Galotto Junior, G. de A. Melo, C.A. Canesin, Single-phase current-source-boost inverter for renewable energy sources, Proc. ISIE 20 (2011) 1118-1123.

[20] G. Saravana Ilango, P. Srinivasa Rao, A. Karthikeyan, C. Nagamani, Single-stage sine-wave inverter for an autonomous operation of solar photovoltaic energy conversion system, Renew. Energy, 35 (1) (January 2010) 275-282.

[21] R.W. Erickson, D. Maksimović, Fundamentals of Power Electronics, second ed., Kluwer Academic Publisher, USA, 2001.

[22] V. Vorperian, Simplified analysis of PWM converters using model of PWM switch. Continuous conduction mode, IEEE Trans. Aerosp. Electron. Syst. 26 (3) (May 1990) 490-496.

[23] A. Isidori, Nonlinear Control Systems, third ed., Springer Verlag, London, United Kingdom, 1995.

[24] G. Chu, C.K. Tse, Siu Chung Wong, Siew-Chong Tan, A unified approach for the derivation of robust control for boost PFC converters, IEEE Trans. Power Electron. 24 (11) (November 2009) 2531-2544.

[25] M.J. Kurtz, M.A. Henson, Input-output linearizing control of constrained nonlinear processes, J. Process Control 7 (1) (February 1997) 3-17.

[26] S. Boyd, L. El Ghaoui, E. Feron, V. Balakrishnan, Linear matrix inequalities in system and control theory, Soc. Ind. Appl. Math. 15 (s. 1) (1994).

[27] H.M. Hassan, A.L. ElShafei, W.A. Farag, M.S. Saad, A robust LMI-based pitch controller for large wind turbines, Renew, Energy, 44 (August 2012) 63-71.

[28] M. Chilali, P. Gahinet, Ho design with pole placement constraints: an LMI approach, IEEE Trans. Autom. Control 41 (3) (March 1996) 358-367.

[29] J. Lofberg, YALMIP: a toolbox for modeling and optimization in MATLAB, in: Proc. of CACSD, vol. 13, 2004, pp. 284-289.

[30] IEEE recommended practice for utility interface of photovoltaic (PV) systems, IEEE Std 929-2000 (2000).

[31] P. Mahat, Z. Chen, B. Bak-Jensen, T. Matsuoka, Review of islanding detection methods for distributed generation, in: Proc. of DRPT, vol. 3, 2008, pp. 2743-2748.

[32] IEC Standard 62116:2008, Test Procedure of Islanding Prevention Measures for Utility-interconnected Photovoltaic Inverters, first ed., IEC Standard, 2008 [s.l.]. 